\title{
Current Mode Biquad Filter with Minimum Component Count
}

\author{
Bhartendu Chaturvedi and Sudhanshu Maheshwari \\ Department of Electronics Engineering, Z. H. College of Engineering and Technology, AMU, Aligarh 202 002, India \\ Correspondence should be addressed to Bhartendu Chaturvedi, bhartendu.prof@gmail.com
}

Received 26 January 2011; Accepted 28 April 2011

Academic Editor: I. A. Khan

Copyright ( 2011 B. Chaturvedi and S. Maheshwari. This is an open access article distributed under the Creative Commons Attribution License, which permits unrestricted use, distribution, and reproduction in any medium, provided the original work is properly cited.

\begin{abstract}
The paper presents a new current mode biquadratic filter with one input and three outputs using differential voltage current conveyor (DVCC) and four passive components. The proposed circuit can simultaneously realize low-pass, band-pass, and highpass filter functions without changing the circuit topology and passive elements. The circuit exhibits a good frequency performance and low-sensitivity figures. PSPICE simulation using $0.5 \mu \mathrm{m}$ CMOS parameters are given to validate the proposed circuit. The circuit provides a simple yet novel solution to the current-mode filtering after appropriate incorporation of current sensing elements in form of current buffers.
\end{abstract}

\section{Introduction}

Current-mode circuits have been receiving considerable attention owing to their potential advantages such as wider bandwidth, greater linearity, higher slew rate, wider dynamic range, simple circuitry, and low power consumption compared to voltage-mode circuits [1-3]. Current-mode analog signal filtering has also received a lot of attention in the recent past. Thus, several multifunction or universal biquadratic filters using current conveyors have been reported in the literature [4-36]. Recently, CDTA has also been used for currentmode filtering application [5]. The circuit in [6] realizes three basic filtering functions and uses all grounded components. The circuit [7] is based on minimum number of passive elements. Another current mode work employs only one active element in the form of a CFOA [8]. One multifunction filter using two CDBAs was also reported [9]. Current mode filters [17] benefit from high output impedance and use of grounded components. An active element which also has merged as a potential candidate for realizing filter circuits is a differential voltage current conveyor $[10,11,17-19,25,26]$. The works based on DVCC present a KHN biquad $[10,11]$ is benefiting from high output impedance outputs.

This paper presents a new second-order current mode filter circuit employing grounded components. The circuit uses a minimum number of components required to achieve a second-order transfer function. Three types of transfer functions are available at once, without any circuit modification. Moreover, the circuits using grounded components are beneficial from fabrication point of view. The non-ideal study and parasitic effects are also given. The new circuit is verified using PSPICE, a powerful tool for verifying new circuits based on active elements, which are either not commercially available or their implementation using available ICs is not very economical.

\section{Proposed Circuit}

2.1. Circuits' Description. The symbol and CMOS implementation of differential voltage current conveyor (DVCC) are shown in Figures 1 and 2, respectively, and are characterized by the following port relationship:

$$
V_{X}=V_{Y 1}-V_{Y 2}, \quad I_{Y 1}=I_{Y 2}=0, \quad I_{Z+}=+I_{X} .
$$

A new current-mode biquadratic filter with one input terminal and three output terminals is proposed. The given circuit uses one differential voltage current conveyor (DVCC), two grounded resistors and two grounded capacitors. The given circuit can realize the standard filter functions: low-pass, band-pass, and high-pass, simultaneously without changing the passive elements. The given circuit uses one DVCC, two grounded resistors, and two grounded capacitors. The use of 


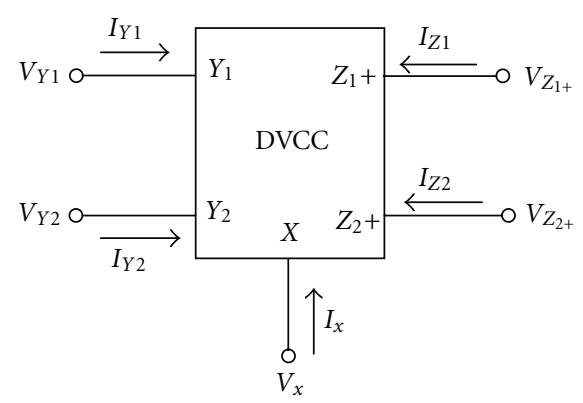

Figure 1: Symbol of DVCC with two $Z+$ stages.

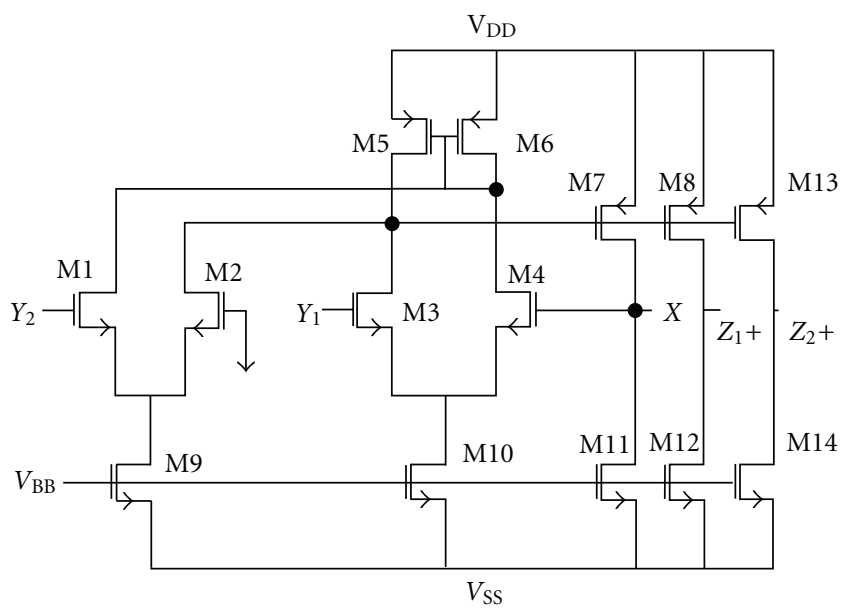

Figure 2: CMOS implementation of DVCC with two $Z+$ stages.

only grounded components is particularly attractive for IC implementation.

2.2. Circuit Analysis. The proposed circuit of Figure 3 is analyzed using (1). The transfer functions can be expressed as

$$
\begin{aligned}
\frac{I_{\mathrm{LP}}}{I_{\text {in }}} & =-\frac{1 / C_{1} C_{2} R_{1} R_{2}}{s^{2}+s\left[1 / C_{2} R_{2}-1 / C_{2} R_{1}+1 / C_{1} R_{1}\right]+1 / C_{1} C_{2} R_{1} R_{2}}, \\
\frac{I_{\mathrm{BP}}}{I_{\text {in }}} & =-\frac{s / C_{1} R_{1}}{s^{2}+s\left[1 / C_{2} R_{2}-1 / C_{2} R_{1}+1 / C_{1} R_{1}\right]+1 / C_{1} C_{2} R_{1} R_{2}}, \\
\frac{I_{\mathrm{HP}}}{I_{\text {in }}} & =\frac{s^{2}+s\left[1 / C_{2} R_{2}-1 / C_{2} R_{1}\right]}{s^{2}+s\left[1 / C_{2} R_{2}-1 / C_{2} R_{1}+1 / C_{1} R_{1}\right]+\left(1 / C_{1} C_{2} R_{1} R_{2}\right)} \\
& =\frac{s^{2}}{s^{2}+s\left[1 / C_{2} R\right]+1 / C_{1} C_{2} R^{2}} \quad\left(\text { for } R_{1}=R_{2}=R\right) .
\end{aligned}
$$

From (2), it can be seen that a low-pass response is obtained from $I_{\mathrm{LP}}$, a band-pass response is obtained from $I_{\mathrm{BP}}$, highpass response is obtained from $I_{\mathrm{HP}}$ under the condition $R_{1}=$ $R_{2}=R$.
In low-pass and band-pass responses, the resonance angular frequency $\omega_{0}$ and the quality factor $Q$ are given by

$$
\begin{gathered}
\omega_{0}=\sqrt{\frac{1}{C_{1} C_{2} R_{1} R_{2}}}, \\
Q=\frac{\sqrt{C_{1} C_{2} R_{1} R_{2}}}{C_{1} R_{1}-C_{1} R_{2}+C_{2} R_{2}} .
\end{gathered}
$$

It may be further noted that for high-pass response, the resistors are matched as $R_{1}=R_{2}=R$, so the resonance angular frequency $\omega_{0}$ and the quality factor $Q$ of the above (3) become

$$
\begin{gathered}
\omega_{0}=\frac{1}{R} \sqrt{\frac{1}{C_{1} C_{2}}}, \\
Q=\sqrt{\frac{C_{1}}{C_{2}}} .
\end{gathered}
$$

The high-pass gain, low-pass gain and band-pass gain, are given by

$$
H_{\mathrm{HP}}=1 ; \quad H_{\mathrm{LP}}=1 ; \quad H_{\mathrm{BP}}=\frac{R_{2} C_{2}}{R_{2} C_{2}+R_{1} C_{1}-R_{2} C_{1}} .
$$

In (6), the high-pass gain and low-pass gain are in unity, and the band pass gain with equal resistor design also becomes unity. Sensitivity figures of the filter parameters (3) for the proposed circuit is analyzed. Pole frequency sensitivity is found to be 0.5 in magnitude for all elements

$$
S_{R_{1}}^{\omega_{0}}=S_{R_{2}}^{\omega_{0}}=S_{C_{1}}^{\omega_{0}}=S_{C_{2}}^{\omega_{0}}=-\frac{1}{2}
$$

Pole- $Q$ sensitivity for resistive and capacitive elements is, respectively, found as

$$
\begin{aligned}
& S_{R_{1}}^{Q}=\frac{C_{2} R_{2}-C_{1} R_{2}-C_{1} R_{1}}{2\left[C_{2} R_{2}+C_{1} R_{1}-C_{1} R_{2}\right]}, \\
& S_{R_{2}}^{Q}=\frac{C_{1} R_{2}+C_{1} R_{1}-C_{2} R_{2}}{2\left[C_{2} R_{2}+C_{1} R_{1}-C_{1} R_{2}\right]}, \\
& S_{C_{1}}^{Q}=\frac{C_{1} R_{2}+C_{2} R_{2}-C_{1} R_{1}}{2\left[C_{2} R_{2}+C_{1} R_{1}-C_{1} R_{2}\right]}, \\
& S_{C_{2}}^{Q}=\frac{C_{1} R_{1}-C_{2} R_{2}-C_{1} R_{2}}{2\left[C_{2} R_{2}+C_{1} R_{1}-C_{1} R_{2}\right]} .
\end{aligned}
$$

For equal capacitor and resistor design, the sensitivity of pole- $Q$ to resistive and capacitive elements becomes less than unity in magnitude. It is to be noted that a new active element,namely, current backward transconductance Amplifier (CBTA), has been recently used for current and voltage mode filtering applications [33]. The recent work includes current mode universal filter with single input and three outputs using single active element and only grounded passive components. The circuit also enjoys low active and passive sensitivities. The novel CBTA-based work employs as many as 22 transistors along with a floating current 


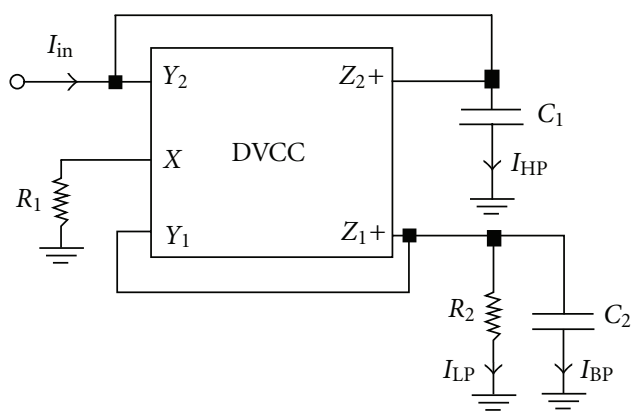

Figure 3: Proposed current-mode biquad filter.

source, which is cumbersome to implement, as compared to the proposed circuit which uses only 10 transistors and no current source. Therefore, the new proposed circuit is lot simpler than the recent novel work [33].

\section{Nonidealities and Parasitic Study}

3.1. Nonideal Analysis. Taking the tracking errors of the DVCC into account, the relationship of the terminal voltages and currents of the DVCC can be rewritten as

$$
\begin{gathered}
V_{X}=\beta_{1} V_{Y 1}-\beta_{2} V_{Y 2}, \quad I_{Y 1}=I_{Y 2}=0, \\
I_{Z 1+}=+\alpha_{1} I_{X}, \quad I_{Z 2+}=+\alpha_{2} I_{X} .
\end{gathered}
$$

Here, $\beta_{1}$ and $\beta_{2}$ are the voltage transfer gains from $Y_{1}$ and $Y_{2}$ terminal, respectively, to the $X$ terminal and $\alpha_{1}$ is the current transfer gain of DVCC from $X$ to $Z_{1+}$ terminal, $\alpha_{2}$ is the current transfer gain of DVCC from the $X$ to $Z_{2+}$ terminal. The above transfer gains deviate unity by the voltage and current transfer errors, which are quite small and technology dependent. Moreover, the transfer gains, instead of being real, are actually frequency dependent with an upper bound on the usable frequency.

The current mode biquad filter of Figure 3 is analyzed using (9) (nonideal characteristic equations), thus transfer functions become as

$$
\begin{aligned}
& \frac{I_{\mathrm{LP}}}{I_{\text {in }}}=-\frac{\frac{\alpha_{1} \beta_{2}}{C_{1} C_{2} R_{1} R_{2}}}{s^{2}+s\left[\frac{1}{C_{2} R_{2}}-\frac{\alpha_{1} \beta_{1}}{C_{2} R_{1}}+\frac{\alpha_{2} \beta_{2}}{C_{1} R_{1}}\right]+\frac{\alpha_{2} \beta_{2}}{C_{1} C_{2} R_{1} R_{2}}}, \\
& \frac{I_{\mathrm{BP}}}{I_{\text {in }}}=-\frac{\frac{s \alpha_{1} \beta_{2}}{C_{1} R_{1}}}{s^{2}+s\left[\frac{1}{C_{2} R_{2}}-\frac{\alpha_{1} \beta_{1}}{C_{2} R_{1}}+\frac{\alpha_{2} \beta_{2}}{C_{1} R_{1}}\right]+\frac{\alpha_{2} \beta_{2}}{C_{1} C_{2} R_{1} R_{2}}}, \\
& \frac{I_{\mathrm{HP}}}{I_{\text {in }}}=\frac{s^{2}+s\left[\frac{1}{C_{2} R_{2}}-\frac{\alpha_{1} \beta_{1}}{C_{2} R_{1}}\right]}{s^{2}+s\left[\frac{1}{C_{2} R_{2}}-\frac{\alpha_{1} \beta_{1}}{C_{2} R_{1}}+\frac{\alpha_{2} \beta_{2}}{C_{1} R_{1}}\right]+\frac{\alpha_{2} \beta_{2}}{C_{1} C_{2} R_{1} R_{2}}},
\end{aligned}
$$

where $\beta_{1}$ and $\beta_{2}$ are the voltage transfer gains of DVCC from the $Y_{1}$ and $Y_{2}$ terminals to the $X$ terminal, respectively, $\alpha_{1}$ is the current transferw gain of DVCC from $X$ to $Z_{1+}$ terminal, $\alpha_{2}$ is the current transfer gain of DVCC from the $X$ to $Z_{2+}$ terminal. Equation (10) show the transfer function of second order low-pass filter, band-pass filter, and high pass filter with nonidealities of DVCC, respectively. And it is to be noted that (10) reduces to (2) for $\alpha_{j}=\beta_{j}=1$ (where $j=1,2$ ).

The resonance angular frequency $\omega_{0}$ and quality factor $Q$ with non idealities are obtained by

$$
\begin{gathered}
\omega_{0}=\sqrt{\frac{\alpha_{2} \beta_{2}}{C_{1} C_{2} R_{1} R_{2}}}, \\
Q=\frac{\sqrt{\alpha_{2} \beta_{2} C_{1} C_{2} R_{1} R_{2}}}{C_{1} R_{1}-\alpha_{1} \beta_{1} C_{1} R_{2}+\alpha_{2} \beta_{2} C_{2} R_{2}},
\end{gathered}
$$

where $\beta_{1}$ and $\beta_{2}$ are the voltage transfer gains of DVCC from the $Y_{1}$ and $Y_{2}$ terminals to the $X$ terminal, respectively, $\alpha_{1}$ is the current transfer gain of DVCC from $X$ to $Z_{1+}$ terminal, $\alpha_{2}$ is the current transfer gain of DVCC from the $X$ to $Z_{2+}$ terminal. It is to be further noted that (11) reduces to (4) and (12) reduces to (5) for $\alpha_{j}=\beta_{j}=1$ (where $j=1,2$ ).

The active and passive pole frequency sensitivity is found to be 0.5 in magnitude for all elements

$$
S_{\alpha_{2}}^{\omega_{0}}=S_{\beta_{2}}^{\omega_{0}}=-S_{R_{1}}^{\omega_{0}}=-S_{R_{2}}^{\omega_{0}}=-S_{C_{1}}^{\omega_{0}}=-S_{C_{2}}^{\omega_{0}}=\frac{1}{2} .
$$

Pole- $Q$ sensitivity for active and passive elements is found as

$$
\begin{aligned}
S_{R_{1}}^{Q} & =\frac{1}{2}\left[\frac{\alpha_{2} \beta_{2} C_{2} R_{2}-\alpha_{1} \beta_{1} C_{1} R_{2}-C_{1} R_{1}}{\alpha_{2} \beta_{2} C_{2} R_{2}+C_{1} R_{1}-\alpha_{1} \beta_{1} C_{1} R_{2}}\right], \\
S_{R_{2}}^{Q} & =\frac{1}{2}\left[\frac{\alpha_{1} \beta_{1} C_{1} R_{2}-\alpha_{2} \beta_{2} C_{2} R_{2}+C_{1} R_{1}}{\alpha_{2} \beta_{2} C_{2} R_{2}+C_{1} R_{1}-\alpha_{1} \beta_{1} C_{1} R_{2}}\right], \\
S_{C_{1}}^{Q} & =\frac{1}{2}\left[\frac{\alpha_{2} \beta_{2} C_{2} R_{2}+\alpha_{1} \beta_{1} C_{1} R_{2}-C_{1} R_{1}}{\alpha_{2} \beta_{2} C_{2} R_{2}+C_{1} R_{1}-\alpha_{1} \beta_{1} C_{1} R_{2}}\right], \\
S_{C_{2}}^{Q} & =\frac{1}{2}\left[\frac{C_{1} R_{1}-\alpha_{2} \beta_{2} C_{2} R_{2}-\alpha_{1} \beta_{1} C_{1} R_{2}}{\alpha_{2} \beta_{2} C_{2} R_{2}+C_{1} R_{1}-\alpha_{1} \beta_{1} C_{1} R_{2}}\right], \\
S_{\alpha_{1}}^{Q} & =S_{\beta_{1}}^{Q}=\frac{\alpha_{1} \beta_{1} C_{1} R_{2}}{\alpha_{2} \beta_{2} C_{2} R_{2}+C_{1} R_{1}-\alpha_{1} \beta_{1} C_{1} R_{2}}, \\
S_{\alpha_{2}}^{Q}=S_{\beta_{2}}^{Q} & =\frac{1}{2}\left[\frac{C_{1} R_{1}-\alpha_{2} \beta_{2} C_{2} R_{2}-\alpha_{1} \beta_{1} C_{1} R_{2}}{\alpha_{2} \beta_{2} C_{2} R_{2}+C_{1} R_{1}-\alpha_{1} \beta_{1} C_{1} R_{2}}\right],
\end{aligned}
$$

where $\beta_{1}$ and $\beta_{2}$ are the voltage transfer gains of DVCC from the $Y_{1}$ and $Y_{2}$ terminals to the $X$ terminal, respectively, $\alpha_{1}$ is the current transfer gain of DVCC from $X$ to $Z_{1+}$ terminal, and $\alpha_{2}$ is the current transfer gain of DVCC from the $X$ to $Z_{2+}$ terminal. For equal capacitor and resistor design, the sensitivity of pole- $Q$ to active and passive elements becomes within unity in magnitude.

3.2. Effect of DVCC Parasitics. Analogous to the secondgeneration current conveyor (CCII), the DVCC has a small parasitic resistance $R_{X}$ at port $X$ and high output impedance $\left(R_{z} / / C_{z}\right)$ at port $Z$. As the $X$ terminal of the DVCC is 
connected to a resistor, the parasitic resistance at the $X$ terminal of the DVCC $\left(R_{X}\right)$ can be absorbed as a part of the main resistance. As the value of $R_{X 1}$ is much smaller, then the external resistor $\left(R_{1}\right)$, so pole- $\omega_{0}$ of the proposed circuit of second-order current mode biquad filter will not be affected. The effects of the capacitors at port $Y$ and $Z$ of the DVCC are also negligible, because these capacitors are quite small (and process dependent) as compared to the external capacitors. However, the effective values of the capacitors after parasitics' inclusion is given below:

$$
\begin{aligned}
& \left.C_{1} \text { (effective }\right)=C_{1}+C_{Z 2+}+C_{Y 2}, \\
& \left.C_{2} \text { (effective }\right)=C_{2}+C_{Y 1}+C_{Z 1+} .
\end{aligned}
$$

From (15), it is clear that the parasitic capacitances appear in shunt with external capacitors thus ensuring a possibility of predistorting the designed values. Therefore, it is to be concluded that the circuits are not adversely affected by the parasitic capacitances and $X$-terminal resistances. This would be further confirmed in the following section.

3.3. Output Current Sensing. It may next be argued that the output currents are through passive elements. Moreover, the impedance level may also not be desirable and even frequency dependent (where the output is through a capacitor). Additional current sensing elements in form of current followers can be employed for the purpose. It is a well known fact that current conveyor itself can be used to realize an accurate current follower. This would then ensure high impedance current output but at the cost of ungrounding the passive components. All these issues are quite obvious, but keeping in view the simplicity of the proposed circuit topology, this may not be seen as a drawback of the proposed work. Other available work also suffers from similar current sensing problems [32] as compared to many others which actually show high impedance output filter functions $[17,30,34]$. As already pointed out, the current follower is easily realized using a DVCC itself, by utilizing $X$ and $Z$ as input and outputs, respectively (grounding $Y$ terminals). The current follower circuit is shown in Figure 4 for completeness sake. Figure 4(a) realizes a positive current follower, whereas Figure 4(b) realizes a negative (inverting) current follower. The use of current follower would make the passive elements virtually grounded instead of being physically grounded.

\section{Simulation Results}

PSPICE simulations were performed using the CMOS realization of DVCC with $0.5 \mu$ level 3 MOSFET parameters as also listed in Algorithm 1 and Table 1. The supply voltages used were $\pm 2.5 \mathrm{~V}$ and $V_{\mathrm{BB}}=-1.6 \mathrm{~V}$. The proposed circuit of second-order current mode biquad filter (Figure 3) circuit was designed with $Q=1, f_{o}=9.7 \mathrm{MHz}: C_{1}=C_{2}=$ $10 \mathrm{pF}, R_{1}=R_{2}=2 \mathrm{~K} \Omega$. The simulated resonance frequency is same as designed one. The power consumption was found to be $4.9 \mathrm{~mW}$. The simulation results of second-order current-mode biquad are shown in from Figure 5 to Figure 9.
NMOS:

$\mathrm{LEVEL}=3 \mathrm{UO}=460.5 \mathrm{TOX}=1.0 \mathrm{E}-8 \mathrm{TPG}=1 \mathrm{VTO}=.62$ $\mathrm{JS}=1.8 \mathrm{E}-6 \mathrm{XJ}=.15 \mathrm{E}-6 \mathrm{RS}=417 \mathrm{RSH}=2.73 \mathrm{LD}=0.04 \mathrm{E}-6$ $\mathrm{ETA}=0 \mathrm{VMAX}=130 \mathrm{E} 3 \mathrm{NSUB}=1.71 \mathrm{E} 17$

$\mathrm{PB}=0.761 \mathrm{PHI}=0.905 \mathrm{THETA}=0.129 \mathrm{GAMMA}=0.69$ $\mathrm{KAPPA}=0.1 \mathrm{AF}=1 \mathrm{WD}=0.11 \mathrm{E}-6 \mathrm{CJ}=76.4 \mathrm{E}-5 \mathrm{MJ}=0.357$

CJSW $=5.68 \mathrm{E}-10 \mathrm{MJSW}=0.302 \mathrm{CGSO}=1.38 \mathrm{E}-10$

$\mathrm{CGDO}=1.38 \mathrm{E}-10 \mathrm{CGBO}=3.45 \mathrm{E}-10 \mathrm{KF}=3.07 \mathrm{E}-28$

$\mathrm{DELTA}=.42 \mathrm{NFS}=1.2 \mathrm{E} 11$

PMOS:

LEVEL $=3$ UO $=100$ TOX $=1.0 \mathrm{E}-8 \mathrm{TPG}=1 \mathrm{VTO}=-0.58$

$\mathrm{JS}=.38 \mathrm{E}-6 \mathrm{XJ}=0.1 \mathrm{E}-6 \mathrm{RS}=866 \mathrm{RSH}=1.81 \mathrm{LD}=0.03 \mathrm{E}-6$

$\mathrm{ETA}=0 \mathrm{VMAX}=113 \mathrm{E} 3 \mathrm{NSUB}=2.08 \mathrm{E} 17 \mathrm{~PB}=0.991$

$\mathrm{PHI}=0.905$ THETA $=0.120$ GAMMA $=0.76 \mathrm{KAPPA}=2$

$\mathrm{AF}=1 \mathrm{WD}=0.14 \mathrm{E}-6 \mathrm{CJ}=85 \mathrm{E}-5 \mathrm{MJ}=0.429$

CJSW $=4.67 \mathrm{E}-10 \mathrm{MJSW}=.631 \mathrm{CGSO}=1.38 \mathrm{E}-10$

$\mathrm{CGDO}=1.38 \mathrm{E}-10 \mathrm{CGBO}=3.45 \mathrm{E}-10 \mathrm{KF}=1.08 \mathrm{E}-29$

$\mathrm{DELTA}=0.81 \mathrm{NFS}=0.52 \mathrm{E} 11$

Algorithm 1: Model parameters used for simulation.

TABLE 1: Aspect ratios used.

\begin{tabular}{lcc}
\hline Transistors & $W(\mu \mathrm{m})$ & $L(\mu \mathrm{m})$ \\
\hline M1, M2, M3, M4 & 1.6 & 1 \\
M5, M6 & 8 & 1 \\
M7, M8, M9 & 20 & 1 \\
M10, M11 & 29 & 1 \\
M12, M13, M14 & 90 & 1 \\
\hline
\end{tabular}

Figure 5 shows the simulated gain plots of all three responses (high-pass response, low-pass response, and band-pass response). Figure 6 shows the simulated transient output for low-pass with amplitude of $140 \mu \mathrm{A}$ peak to peak at input of 9.7 MHz. Figure 7 shows the simulated transient output for band-pass with amplitude of $180 \mu \mathrm{A}$ peak to peak at input of 9.7 MHz. Figure 8 shows the simulated transient output for high-pass with amplitude of $240 \mu \mathrm{A}$ peak to peak at input of $9.7 \mathrm{MHz}$. The output waveform for high-pass function at $1 \mathrm{GHz}$ frequency is also shown in Figure 9. As it can be seen, there is a close agreement between the theory and the simulation. The T.H.D. of the proposed circuit at all outputs is within $2 \%$, which is low, keeping in view the frequency of operation.

\section{Conclusion}

A new second-order current-mode active filter is presented. It is very simple and contains a minimum number of components required to achieve a second-order transfer function. Three types of transfer functions are available at once, without any circuit modification. However, due to the circuit simplicity, $f o$ and $Q$ are not independently adjustable. The new circuit is suited for high-frequency operation. PSPICE simulations using $0.5 \mu \mathrm{m}$ CMOS parameters support the validity and practical utility of the proposed circuit. 


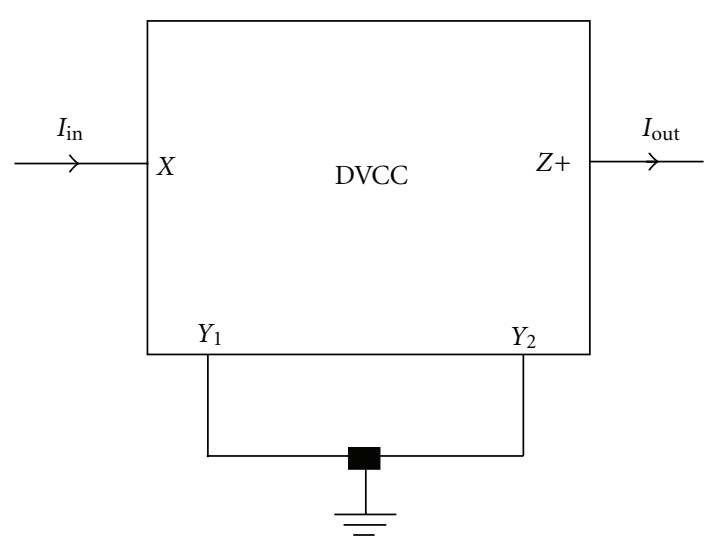

(a)

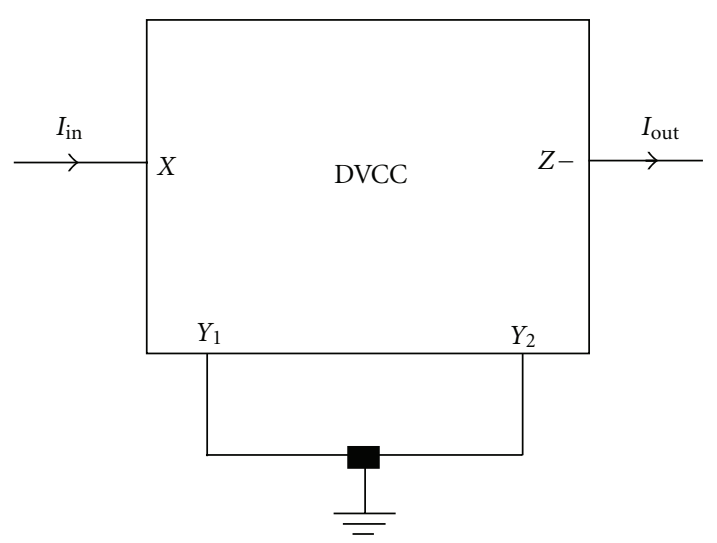

(b)

Figure 4: Circuit of current follower using DVCC (a) Inverting (b) Noninverting.

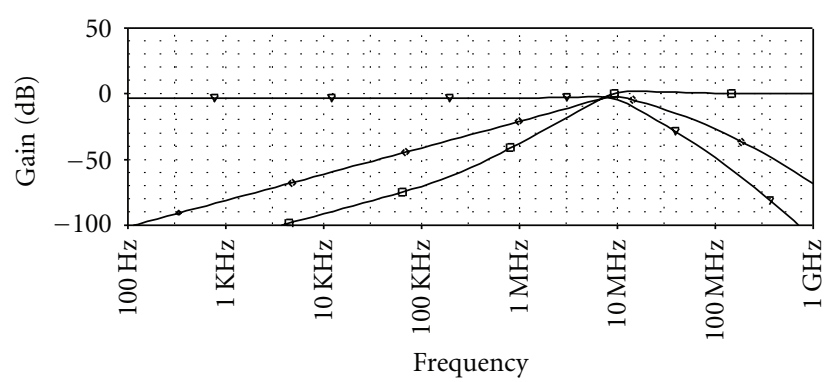

$\square \mathrm{DB}(\mathrm{I}(\mathrm{C} 1) / \mathrm{I}(\mathrm{I}$ in $))$

$\therefore \mathrm{DB}(\mathrm{I}(\mathrm{C} 2) / \mathrm{I}(\mathrm{Iin}))$

$\nabla \mathrm{DB}(I(R 2) / I(\operatorname{Iin}))$

FIGURE 5: Gain plot in $\mathrm{dB}$ showing all three responses.

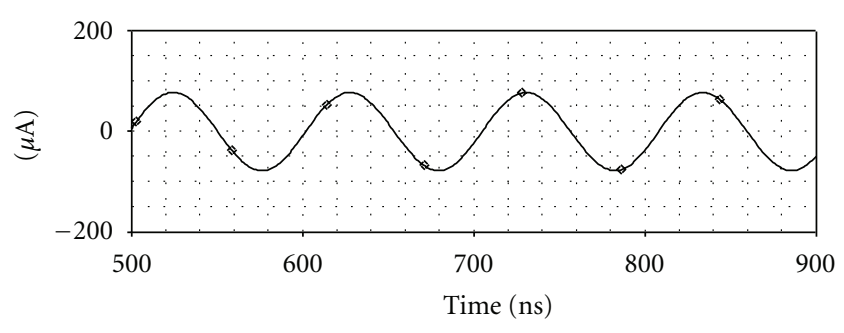

$\diamond I(R 2)$

Figure 6: Low pass output for sinusoidal input of $9.7 \mathrm{MHz}$.

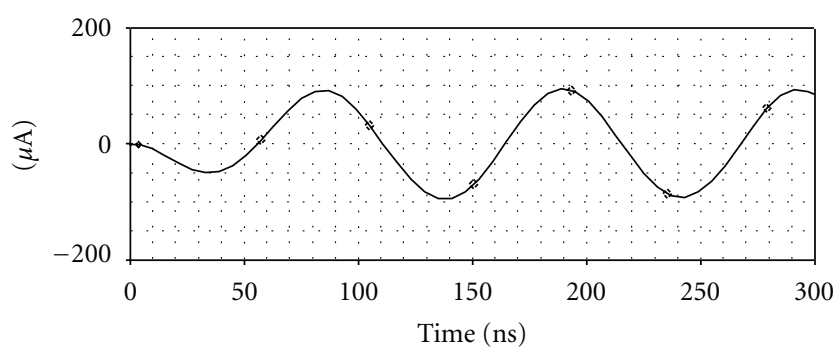

$\therefore I(C 2)$

FIGURE 7: Band pass output for sinusoidal input of 9.7 MHz.

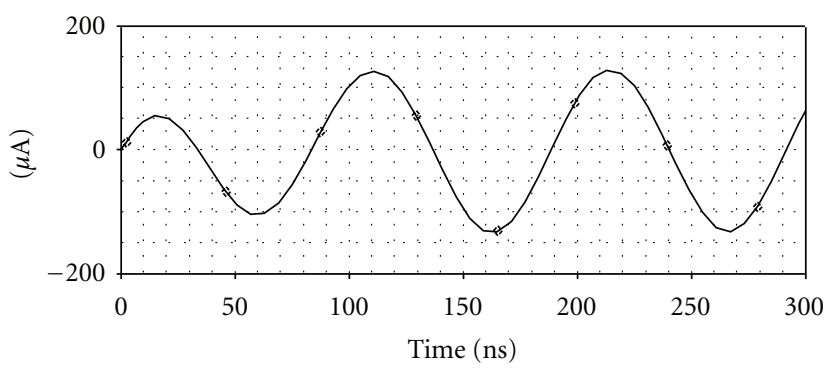

$\diamond I(C 1)$

FIGURE 8: High-pass output for sinusoidal input of $9.7 \mathrm{MHz}$

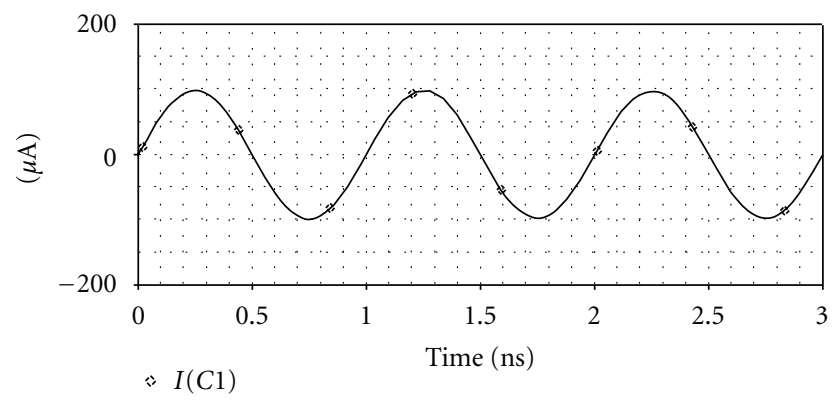

FIGURE 9: High-pass output at $1 \mathrm{GHz}$.

\section{Acknowledgment}

The authors are thankful to the Editor Professor Iqbal A. Khan for getting the paper promptly reviewed and for recommending this paper. 


\section{References}

[1] G. W. Roberts and A. S. Sedra, "All current-mode frequency selective circuits," Electronics Letters, vol. 25, no. 12, pp. 759761, 1989.

[2] B. Wilson, "Recent developments in current conveyors and current-mode circuits," IEE Proceedings G, vol. 137, no. 2, pp. 63-77, 1990.

[3] C. Toumazou, F. J. Lidgey, and D. G. Haigh, Analogue IC Design: The Current-Mode Approach, IEE, York, UK, 1998.

[4] A. M. Soliman, "Current mode universal filter," Electronics Letters, vol. 31, no. 17, pp. 1420-1421, 1995.

[5] D. Biolek and V. Biolková, "Three-CDTA current-mode biquad," WSEAS Transactions on Circuits and Systems, vol. 4, no. 10, pp. 1227-1232, 2005.

[6] M. T. Abuelma'atti and M. H. Khan, "Low component current-mode universal filter," Electronics Letters, vol. 31, no. 25, pp. 2160-2161, 1995.

[7] O. Cicekoglu, "Current-mode biquad with a minimum number of passive elements," IEEE Transactions on Circuits and Systems II, vol. 48, no. 2, pp. 221-222, 2001.

[8] R. K. Sharma and R. Senani, "Universal current mode biquad using a single CFOA," International Journal of Electronics, vol. 91, no. 3, pp. 175-183, 2004.

[9] A. U. Keskin and E. Hancioglu, "Current mode multifunction filter using two CDBAs," International Journal of Electronics and Communications, vol. 59, no. 8, pp. 495-498, 2005.

[10] M. A. Ibrahim, S. Minaei, and H. Kuntman, "A $22.5 \mathrm{MHz}$ current-mode KHN-biquad using differential voltage current conveyor and grounded passive elements," International Journal of Electronics and Communications, vol. 59, no. 5, pp. 311318, 2005.

[11] S. Minaei and M. A. Ibrahim, "A mixed-mode KHN-biquad using DVCC and grounded passive elements suitable for direct cascading," International Journal of Circuit Theory and Applications, vol. 37, no. 7, pp. 793-810, 2009.

[12] S. Minaei and S. Türköz, "New current-mode currentcontrolled universal filter with single input and three outputs," International Journal of Electronics, vol. 88, no. 3, pp. 333-337, 2001.

[13] E. Yuce and S. Minaei, "Universal current-mode filters and parasitic impedance effects on the filter performances," International Journal of Circuit Theory and Applications, vol. 36, no. 2, pp. 161-171, 2008.

[14] S. Minaei, O. Cicekoglu, H. Kuntman, and S. Türköz, "High output impedance current-mode lowpass, bandpass and highpass filters using current controlled conveyors," International Journal of Electronics, vol. 88, no. 8, pp. 915-922, 2001.

[15] S. Minaei, O. Cicekoglu, H. Kuntman, G. Dündar, and A. Cerid, "New realizations of current-mode and voltagemode multifunction filters without external passive elements," International Journal of Electronics and Communications, vol. 57, no. 1, pp. 63-69, 2003.

[16] E. Yuce, S. Tokat, S. Minaei, and O. Cicekoglu, "Stability problems in universal current-mode filters," International Journal of Electronics and Communications, vol. 61, no. 9, pp. 580-588, 2007.

[17] S. Maheshwari, "Current-mode filters with high output impedance and employing only grounded components," WSEAS Transactions on Electronics, vol. 5, no. 6, pp. 238-243, 2008.

[18] H. O. Elwan and A. M. Soliman, "Novel CMOS differential voltage current conveyor and its applications," IEE Proceedings: Circuits, Devices and Systems, vol. 144, no. 3, pp. 195-200, 1997.
[19] T. Tsukutani, Y. Sumi, and N. Yabuki, "Novel currentmode biquadratic circuit using only plus type DO-DVCCs and grounded passive components," International Journal of Electronics, vol. 94, no. 12, pp. 1137-1146, 2007.

[20] T. Tsukutani, Y. Sumi, and M. Yabuki, "Electronically tunable current-mode universal biquadratic filter using CCCDBAs," in Proceedings of the International Symposium on Intelligent Signal Processing and Communication Systems (ISPACS '08), vol. 811, pp. 1-4, February 2009.

[21] T. Tsukutani, M. Higashimura, Y. Sumi, and Y. Fukui, "Electronically tunable current-mode active-only biquadratic filter," International Journal of Electronics, vol. 87, no. 3, pp. 307$314,2000$.

[22] T. Tsukutani, Y. Sumi, M. Higashimura, and Y. Fukui, "Current-mode biquad using OTAs and CF," Electronics Letters, vol. 39, no. 3, pp. 262-263, 2003.

[23] T. Katoh, T. Tsukutani, Y. Sumi, and Y. Fukui, "Electronically tunable current-mode universal filter employing CCCIIs and grounded capacitors," in Proceedings of the International Symposium on Intelligent Signal Processing and Communication Systems (ISPACS '06), vol. 12-15, pp. 107-110, December 2006.

[24] T. Tsukutani, Y. Sumi, S. Iwanari, and Y. Fukui, "Novel current-mode biquad using MO-CCCIIS and grounded capacitors," in Proceedings of the International Symposium on Intelligent Signal Processing and Communication Systems (ISPACS '05), vol. 13-16, pp. 433-436, December 2005.

[25] Y. Sumi, T. Tsukutani, and N. Yabuki, "Novel current-mode biquadratic circuit using only plus type DO-DVCCCs," in Proceedings of the International Symposium on Intelligent Signal Processing and Communication Systems (ISPACS '08), vol. 811, pp. 1-4, February 2008.

[26] H. P. Chen and S. S. Shen, "A versatile universal capacitorgrounded voltage-mode filter using DVCCs," ETRI Journal, vol. 29, no. 4, pp. 470-476, 2007.

[27] G. W. Roberts and A. S. Sedra, "A general class of current amplifier-based biquadratic filter circuits," IEEE Transactions on Circuits and Systems I, vol. 39, no. 4, pp. 257-263, 1992.

[28] A. M. Soliman, "Current conveyor filters: classification and review," Microelectronics Journal, vol. 29, no. 3, pp. 133-149, 1998.

[29] H. P. Chen and W. S. Yang, "High-input and low-output impedance voltage-mode universal DDCC and FDCCII filter," IEICE Transactions on Electronics, vol. E91-C, no. 4, pp. 666$669,2008$.

[30] S. Maheshwari and I. A. Khan, "Novel cascadable currentmode translinear-C universal filter," Active and Passive Electronic Components, vol. 27, no. 4, pp. 215-218, 2004.

[31] S. Maheshwari and I. A. Khan, "High performance versatile translinear-C universal filter," Journal of Active and Passive Electronic Devices, vol. 1, pp. 41-51, 2005.

[32] I. A. Khan and M. H. Zaidi, "Multifunctional translinear-C current-mode filter," International Journal of Electronics, vol. 87, no. 9, pp. 1047-1051, 2000.

[33] M. Sagbas, U. E. Ayten, and H. Sedef, "Current and voltage transfer function filters using a single active device," IET Circuits Devices and Systems, vol. 4, pp. 78-86, 2010.

[34] D. Biolek, J. Bajer, V. Biolková, Z. Kolka, and M. Kubíček, “Z copy-controlled gain-current differencing buffered amplifier and its applications," International Journal of Circuit Theory and Applications, vol. 39, no. 3, pp. 257-274, 2011. 
[35] D. Biolek, V. Biolkova, Z. Kolka, and J. Bajer, "Single-input multi-output resistorless current-mode biquad," in Proceedings of the European Conference on Circuit Theory and Design (ECCTD '09), pp. 225-228, August 2009.

[36] A. Ü. Keskin, D. Biolek, E. Hancioglu, and V. Biolková, "Current-mode KHN filter employing current differencing transconductance amplifiers," International Journal of Electronics and Communications, vol. 60, no. 6, pp. 443-446, 2006. 

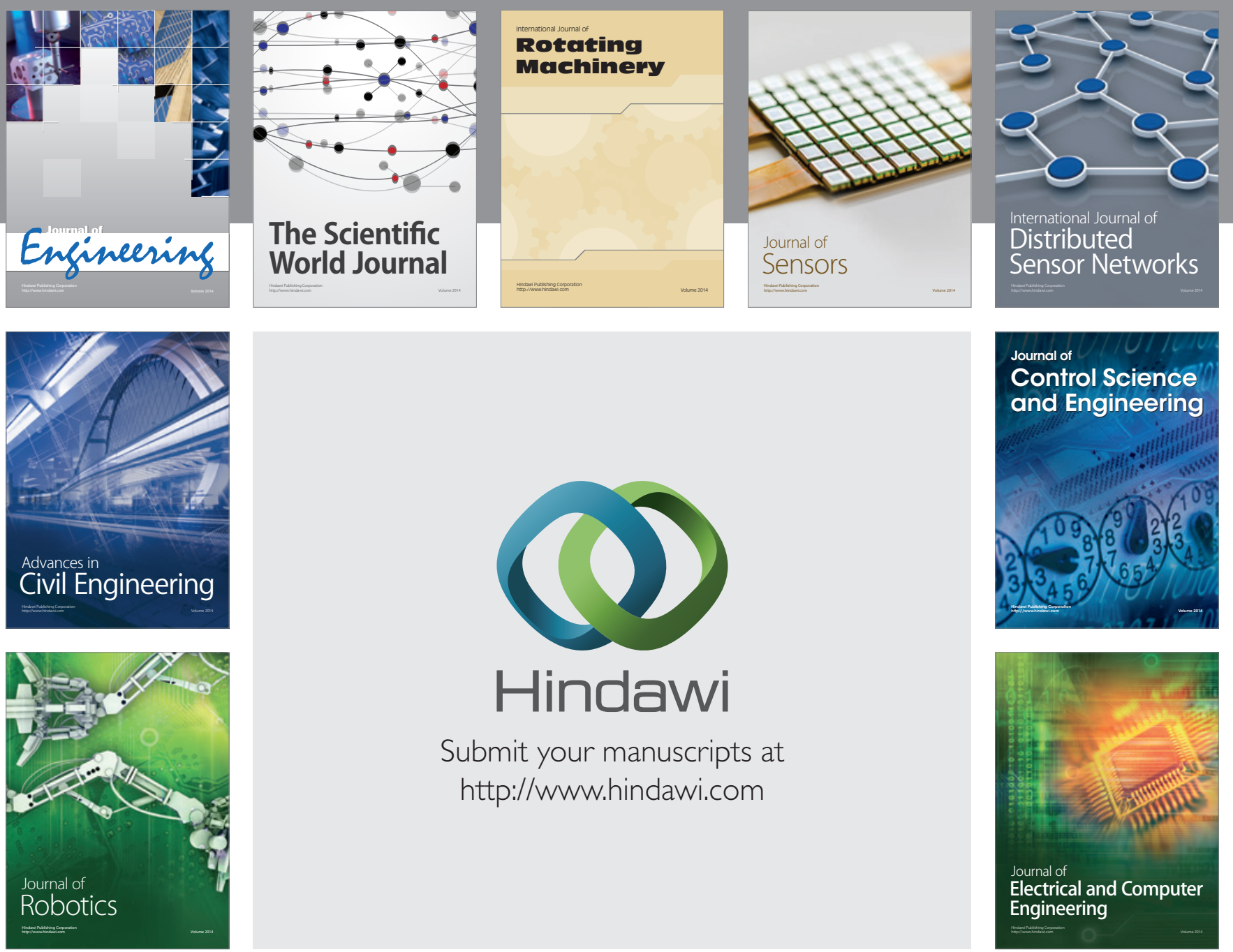

Submit your manuscripts at

http://www.hindawi.com
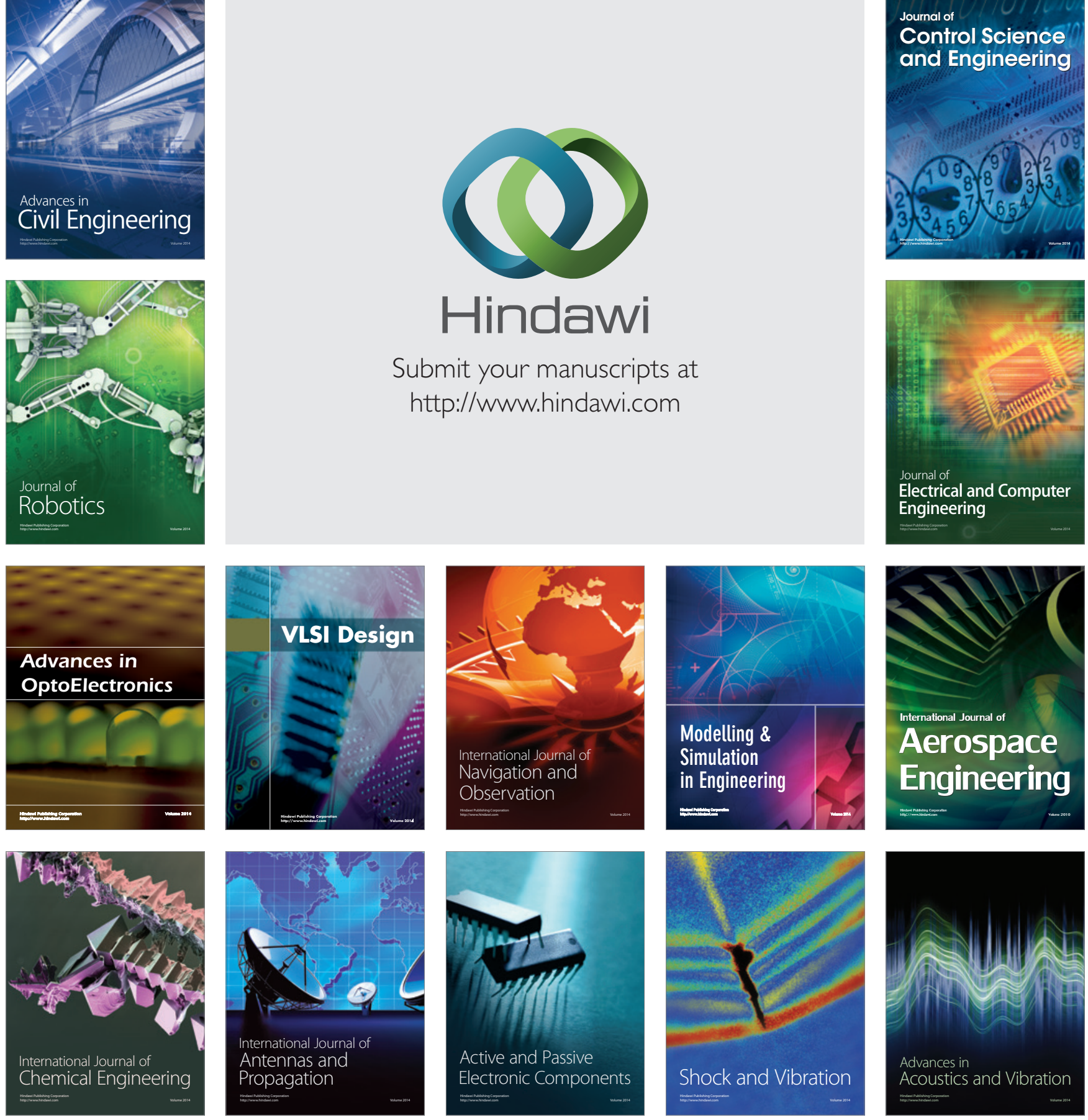